\title{
Incidence of Bovine Clinical Mastitis and Antibiogram of the Isolates in Odisha, India
}

\author{
Sambit Kumar Mishra ${ }^{1}$, Sujata Kumari Panda ${ }^{1}$ and Debiprasanna Das ${ }^{2 *}$ \\ ${ }^{1}$ Animal Disease Research Institute, F\&ARD, Phulnakhara, Cuttack, Odisha - 754001, India \\ ${ }^{2}$ CVSC \& AH, OUAT, Bhubaneswar, India \\ *Corresponding author
}

\section{A B S T R A C T}

\section{Keywords}

Bovine mastitis, MCMT,

Antibiogram, Staphylococcus

Article Info

Accepted:

08 August 2018

Available Online:

10 September 2018
The present study was taken up to evaluate the antibiogram against different mastitogenic pathogens isolated from the milk samples of clinical bovine mastitis cases. A total of 78 milk samples were collected from different dairy farmers of Nialiblock, Odisha and processed in Animal Disease Research Institute (ADRI), Phulnakhara, Cuttack for isolation, identification and antibiogram of pathogens. The samples were screened for mastitis by modified California mastitis test (MCMT). The milk samples were inoculated in BHI broth and incubated for 24-48 hours. Then a loopful of culture was streaked into EMB Agar, Mannitol Salt Agar and Blood Agar. The isolates were identified according to the cultural, morphological and biochemical characteristics as per standard methods. All the isolates were subjected to Kirby-Bauer disc diffusion methods using different antibiotics. Out of 78 samples, 73 samples were revealed to be positive for bacterial growth. Bacterial screening of samples revealed that 22 samples yielded pure culture and 51 samples yielded mixed cultures. The predominant bacterial isolates recovered were Staphylococcus spp $(48.17 \%)$ followed by E. coli $(27.73 \%)$, Streptococcus spp (12.41\%), Klebsiella spp (9.48\%) and Bacillus spp (2.19\%).it was found that Staphylococcus is highly sensitive to Enrofloxacin and Gentamicin followed by Ceftriaxone/ Tazobactam and Ciprofloxacin. The study revealed that $E$. coli is highly sensitive to Chloramphenicol followed by Enrofloxacin, Ciprofloxacin and Gentamicin. The Streptococcus spp is found to be sensitive to Enrofloxacin followed by Ciprofloxacin and Gentamicin. All the isolates are found to be almost resistant against Penicillin G, Oxytetracycline, Ampicillin and Ampicillin/Cloxacillin.

\section{Introduction}

Mastitis is a multi-etiological complex disease, defined as inflammation of parenchyma of mammary glands and is characterized by physical, chemical and usually bacteriological changes in milk and pathological changes in glandular tissues (Radostits et al., 2000). It is a devastating disease causing annual economic loss of Rs 6053.21 crores out of which, Rs 4365.32 crore (70-80\%) has been attributed to subclinical mastitis (Dua et al., 2001). Apart from the economic losses mastitis can have serious implications on public health. Infected milk is serving as a media for transmission of various zoonotic diseases like TB, Brucellosis, Diphtheria, Scarlet fever and Q fever 
(Mahantesh et al., 2011). About 137 species of microorganisms including bacteria, Yeast, fungi and algae are able to cause bovine mastitis. The majority of mastitis incidences are caused by only a few common bacterial pathogens like Staphylococcus spp. (Staphylococcus aureus and Staphylococcus epidermidis), Streptococcus spp (Streptococcus agalactiae, Streptococcus dysgalactiae and Streptococcus uberis), Coliforms (mainly E. coli and Klebsiella pneumoniae) and Actinomyces pyogenes (Sharma, 2010). Coagulase negative Staphylococci and Corynebacterium bovis, two other prevalent pathogens are described as minor pathogens.

Antimicrobials are routinely used for treatment of dairy cattle affected with clinical and subclinical infection (Aarestrup, 2005). The recovery rate is low due to continuous indiscriminate use of antibiotics defying the rational approach of selection of suitable antibiotics after doing culture and sensitivity test. The situation is further worsened by the approach of dairy farmers who prefer to take over the counter medicine without consulting a qualified veterinarian. Therefore the present study was undertaken to study the effectiveness of different antibiotics against mastitogenic isolates.

\section{Materials and Methods}

The specimen for the present research work comprised of milk samples obtained from clinical cases of bovine mastitis from dairy farmers of Niali block of Cuttack district. The samples were processed in Animal Disease Research Institute (ADRI), Phulnakhara, Cuttack for isolation, identification and antibiogram of mastitis pathogens. All the samples were screened for mastitis by Modified California mastitis test (MCMT). Each sample was taken by means of a sterile inoculating loop and inoculated into liquid media (BHI Broth) followed by incubation for
24 to $48 \mathrm{hrs}$ at $37^{\circ} \mathrm{C}$. A loopfull of culture was streaked into Muller Hinton Agar (MHA), Eosin Methylene Blue Agar (EMB), Mannitol Salt Agar (MSA) and Blood agar followed by $24 \mathrm{hr}$ of incubation at $37^{\circ} \mathrm{C}$.

The different colonies were observed and identified according to their colony characteristics and growth in selective media. The morphological characteristics were studied by examination of Gram stained smears. The isolates were identified according to the cultural, morphological and biochemical characteristics as per the methods of Cruickshank et al., (1975).

All the isolates were subjected to in vitro antibiotic sensitivity test as per Kirby- Bauer disc diffusion methods using 14 no. of antibiotic discs procured from Hi-Media Pvt. Ltd. such as Ceftriaxone/Tazobactam (30/10mcg), Ceftriaxone (30 mcg), cefoperazone (30 mcg), ceftizoxime (30 mcg), Ciprofloxacin (5mcg), cefuroxime (30 mcg), Ampicillin/cloxacillin (10mcg), Gentamicin (10mcg), Amoxycillin/Sulbactam (30/15mcg), Chloramphenicol (30mcg), Enrofloxacin (10mcg), Penicillin G (10units), Oxytetracycline (30 mcg) and Ampicillin (2mcg).

The inoculum was prepared by transferring 2 to 3 colonies from pure culture to BHI broth followed by incubation at $37^{\circ} \mathrm{C}$ for 6 to $8 \mathrm{hr}$ until turbidity appears. The standardized inoculum was then swabbed on to the MHA plate. Then the antibiotic discs were then placed aseptically equidistant from each other on the surface of MHA plate. The plates were incubated at $37^{\circ} \mathrm{C}$ for 24 to $48 \mathrm{hrs}$. The diameter of zone of inhibition was measured and compared with the values listed in the standard chart provided by the manufacturer on the basis of which isolates were categorized as sensitive, intermediate and resistant to the antimicrobials. 


\section{Results and Discussion}

In this study, a total of 78 number of milk samples were examined out of which 73 samples were found to be positive and in 5 samples, no growth has been observed in liquid as well as solid media which may be due to prior medication within 72 hours before collection in udder. Bacteriological screening of samples revealed that out of 73 samples 22 samples yielded pure culture and remaining 51 samples yielded mixed culture. The pure culture revealed presence of Staphylococcus, Streptococcus and E. coli whereas mixed culture showed presence of Klebsiella and Bacillus in addition to the isolates of pure culture.

The predominant bacterial isolates recovered were Staphylococcus spp (48.17\%) followed by Escherichia Coli $(27.73 \%)$ followed by Streptococcus spp (12.41\%), Klebsiella Spp $(9.48 \%)$ and Bacillus Spp (2.19\%). The frequency of isolation of different bacterial species is depicted in Table 1.

In the present study, prevalence of Staphylococcus is high followed by E. coli and Streptococcus spp which is in agreement with the earlier reports of Aarestrup et al., (1995),
Sumathi et al., (2008) and Junaidu et al., (2011). Staphylococci are the most important and prevalent mastitogenic organisms globally including India. The prevalence of Staphylococcus spp may be due to ubiquitous nature of the organism and the drug resistance shown by them due to biofilm production. It may be associated with incomplete milking especially when the lesions in the udder are painful. The prevalence of $E$. coli is due to poor hygienic condition in the shed. The prevalence of Streptococcus spp may be due to poor dairy practice methods. The Bacillus spp is present in soil, water and manure. The bacteria infects animal via teat canal as reported by Mahantesh et al., (2011).

\section{Antibiogram of the isolates}

Staphylococcus is the most important and prevalent mastitogenic organism occurring globally including India (Sumathi et al., 2008). In the present study, it was found that Staphylococcus is highly sensitive to Enrofloxacin and Gentamicin followed by Ceftriaxone/Tazobactam and Ciprofloxacin (Table 2). This is well in agreement with many earlier reports by Sumathi et al., (2008), Kaliwal et al., (2011) and Dhakal et al., (2007).

Table.1 Frequency of different mastitogenic isolates from clinical mastitis samples

\begin{tabular}{|l|l|c|c|}
\hline S. No. & Name of the bacteria & Number of isolates & Percentage (\%) \\
\hline $\mathbf{1}$ & Staphylococcus spp & 66 & 48.17 \\
\hline $\mathbf{2}$ & Streptococcus spp & 17 & 12.41 \\
\hline $\mathbf{3}$ & E. coli & 38 & 27.73 \\
\hline $\mathbf{4}$ & Klebsiella spp & 13 & 9.48 \\
\hline $\mathbf{5}$ & Bacillus spp & 3 & 2.19 \\
\hline
\end{tabular}


Table.2 Sensityvity pattern of microorganism isolated from clinical mastitis to various antimicrobial agents

\begin{tabular}{|l|l|l|l|l|l|l|l|l|l|}
\hline Name of the antibiotics & \multicolumn{3}{|l|}{ Staphylococcus } & \multicolumn{3}{|l|}{ Streptococcus } & \multicolumn{3}{l|}{ E. coli } \\
& S & I & R & S & I & R & S & I & R \\
\hline Ampicillin & 0 & 2 & 64 & 0 & 2 & 15 & 0 & 0 & 38 \\
\hline Ampicillin/Cloxacillin & 0 & 4 & 62 & 0 & 3 & 14 & 0 & 0 & 38 \\
\hline Amoxycillin/Sulbactam & 2 & 60 & 4 & 4 & 11 & 2 & 0 & 31 & 7 \\
\hline Chloramphenicol & 56 & 8 & 2 & 10 & 6 & 1 & 36 & 1 & 1 \\
\hline Ciprofloxacin & 58 & 8 & 0 & 15 & 2 & 0 & 32 & 3 & 3 \\
\hline Ceftriaxone & 52 & 8 & 6 & 9 & 6 & 2 & 18 & 17 & 3 \\
\hline Ceftriaxone/Tazobactam & 58 & 8 & 0 & 11 & 4 & 2 & 20 & 15 & 3 \\
\hline Cefoperazone & 51 & 8 & 7 & 9 & 5 & 3 & 16 & 15 & 7 \\
\hline Cefuroxime & 36 & 21 & 9 & 8 & 4 & 5 & 14 & 16 & 8 \\
\hline Ceftizoxime & 40 & 18 & 8 & 8 & 4 & 5 & 13 & 14 & 11 \\
\hline Enrofloxacin & 63 & 3 & 0 & 16 & 1 & 0 & 33 & 4 & 1 \\
\hline Gentamicin & 60 & 5 & 1 & 12 & 3 & 2 & 27 & 9 & 2 \\
\hline Penicillin G & 0 & 0 & 66 & 0 & 0 & 17 & 0 & 0 & 38 \\
\hline Oxytetracycline & 0 & 5 & 61 & 0 & 3 & 14 & 0 & 6 & 32 \\
\hline
\end{tabular}

The incidence of mastitis by E. coli may have been due to poor hygienic condition (Bradley, 2002). Current study revealed that E. coli is highly sensitive towards Chloramphenicol followed by Enrofloxacin, Ciprofloxacin and Gentamicin (Table 2). It is in accordance of the report by Mohanty et al., (2013). Streptococcus spp in the current study was found to be sensitive to Enrofloxacin followed by Ciprofloxacin and Gentamicin. Jain et al., (2012) also reported the similar result.

All the isolates are found to be almost resistant against Penicillin G, Oxytetracycline, Ampicillin and Ampicillin/ Cloxacillin. The rate of Penicillin resistance $(100 \%)$ in the current study is much higher than those reported by other workers like Rajala-Schultz et al., (2009) and Kenar et al., (2012), Mahami et al., (2011) reported 100\% resistance against Oxytetracycline which contradicts the current study. Resistance to Penicillin in Staphylococcus is associated with the production of Beta Lactamase and low affinity penicillin binding protein Leelahapongsathan et al., (2014). The overuse and improper selection of antimicrobial drugs to reduce infection of mammary glands may lead to lower production and development of resistant bacteria. In the current study the prevalence of Staphylococcus was found to be maximum followed by $E$. coli and Streptococcus. These three isolates showed high sensitivity to Enrofloxacin, Gentamicin and Ciprofloxacin. There is need to enhance the awareness of farmers to go for antibiotic sensitivity test while choosing the drug for mastitis.

\section{References}

Aarestrup, F. M. 2005: Veterinary drug usage and antimicrobial resistance in bacteria of animal origin. Basic \& Clinical Pharmacology \& Toxicology, vol. 96 (4), 2005, p. 271-281.

Aarestrup, F.M, Wegener, H.C., Rosdahl, V.T. and Jensen, London. N.E (1995) Staphylococcal and other bacterial 
species associated with intramammary infection in Danish dairy herds. Acta veterinaria Scandinavica 36:475-487.

Bansal B.K, Gupta D.K. Economic analysis of bovine mastitis in India and Punjab A review. Indian J. Dairy Sci. 2009; 62 (5):337-345.

Bauer A.W, Kieby W.M.M, Shrenis J.C, Turck M. Antibiotic susceptibity testing by a standardized single disc diffusion method. Am. J. Clin. Pathol. 1966; 45:453-496.

Bhat, A.M., Soodan, J.S., Singh, R., Dhobi, I.A., Hussain, T., Dar, M.Y., Mir, M. (2017). Incidence of bovine clinical mastitis in Jammu region and antibiogram of isolated pathogens, Veterinary World10 (8):984-989.

Bhutto A, Murray D.R, Woldehiwet Z. Udder shape and teat-end lesions as potential risk factors for high somatic cell counts and intra-mammary infections in dairy cows. Vet. J. 2010; 183:63-67.

Bradley, A. J. (2002) Bovine mastitis an evolving disease.. The Vet. J. 164: 116128.

Cruickshank, R., Duguid, J.P., Marmion, B.P. and Swain, R.H.A. (1975) Medical Microbiology. Vol. II, 12th edn, Crurchill Livingstone, New York, 3157p \& 96-218p.

De Vliegher S, Fox L.K, Piepers S, McDougall S, Barkema H.W. Mastitis in dairy heifers: Nature of the disease, potential impact, prevention, and control. J. Dairy Sci. 2012; 95:10251040.

Dhakal I.P, Dhakal P, Koshihara T, Nagahata H. Epidemology and bacteriology survey of buffalo mastitis in Nepal. J. Vet. Med. Sci. 2007; 69:1241-1245.

Dua, K. (2001). Incidence, etiology and estimated economic losses due to mastitis in Punjab and in India- An update. Indian Dairyman, 53 (10): 4148.
Jain, B., Tewari, A., Bhandari, B.B and Jhala, M.K. (2012) Antibiotic resistance and virulence genes in Streptococcus agalactiae isolated from cases of bovine subclinical mastitis. Vet. Archiv. 82

Junaidu, A.U., Salihu, M.D., Tambuwala, F.M., Magaji, A.A. and Jaafaru, S. (2011). Adv.in Appli.sci.Res.2:290-94.

Kaliwal N.B, Singh H.S, Kumar R.B. Antimicrobial sensitivity of coagulase negative Staphylococci from bovine mastitis in Karnataka. Indian Vet. J. 2011; 23 (3):115-118.

Keane O.M, Budd K.E, Flynn J, McCoy F. Pathogen profile of clinical mastitis in Irish milk-recording herds reveals a complex aetiology. Vet. Rec. 2013; 173:17.

Kenar B, Kuyucuoglu Y, Şeker E. Antibiotic susceptibility of coagulase-negative Staphylococci isolated from bovine subclinical mastitis in Turkey. Pak. Vet. J. 2012; 32 (3):390-393.

Khan, A.Z., Khan, A., Hayat, C. S., Munir, Z. and Ayaz, U. Prevalence of mastitis in buffaloes and antibiotic sensitivity profiles of isolates. Pak. J. LifeSoc. Sci. 2 (1):73-75.

Kurjogi M.M, Kaliwal B.B. Prevalence and antimicrobial susceptibility of bacteria isolated from bovine mastitis. Adv. Appl. Sci. Res. 2011; 2 (6):229-235.

Leelahapongsathon K, Schukken Y.H, Suriyasathaporn W. Quarter, cow, and farm chance factors for inframammary infections with major pathogens relative to minor pathogens in Thai dairy cows. Trop. Anim. Health Prod. 2014; 46:1067-1078.

Mahami T, Odonkor S, Yaro M, Adu-Gyamfi A. Prevalence of antibiotic resistant bacteria in milk sold in Accra. Int. Res. J. Microbiol. 2011; 2 (4):126-132.

Mahantesh, M. K. and Basappa, B. K. (2011) Prevalence and antimicrobial susceptibility of bacteria isolated from 
bovine mastitis. Adv. Appl. Sci. Res 228 (6):229-235

Mohanty NN, Das P, Pany SS, Sarangi LN, Ranabijuli S and Panda HK (2013). Isolation and antibiogram of Staphylococcus, Streptococcus and E. coli isolates from clinical and subclinical cases of bovine mastitis, Veterinary World, 6(10): 739-743.

Paduch J.H, Mohr E, Krömker V. The association between teat end hyperkeratosis and teat canal microbial load in lactating dairy cattle. Vet. Microbiol. 2012; 158: 353-359.

Quinn P.J, Carter M.E, Markey B, Carter G.R. Clinical Veterinary Microbiology. London: Wolf/Mosby; 2004.

Radostitis, O.M., Gay, C.C., Blood, D.C. and Funchcliff, K. antibiogram of isolates from cross bred cows. W. (2000) Veterinary medicine: A text book of the disease of cattle, sheep, goat, horse and pigs. 9th Edition W.B. Saunders, London.

Rajala-Schultz P.J, Torres A.H, Degraves F.J, Gebreyes W.A, Patchanee P. Antimicrobial resistance and genotypic characterization of coagulase-negative Staphylococci over the dry period. Vet. Microbiol. 2009; 134:55-64.

Ranjan R, Gupta M.K, Singh K.K. Study of bovine mastitis in different climatic conditions in Jharkhand, India. Vet. World. 2011; 4:205-208.
Riekerink O, Barkema H.W, Kelton D.F, Scholl D.T. Incidence rate of clinical mastitis on Canadian dairy farms. J. Dairy Sci. 2008; 91 (4):1366-1377.

Sharma, D. K. -Jallewar, P. K. - Sharma, K. K. 2010: Antibiogram of bacteria isolated from bovine subclinical mastitis. Indian Veterinary Journal, vol. 87 (4), 2010 , p. 407.

Sudhan N.A, Singh R, Singh M, Soodan J.S. Studies on prevalence, etiology and diagnosis of subclinical mastitis among crossbred cows. Indian J. Anim. Res. 2005; 39 (2):127-130.

Sumathia B.R, Veeregowda B.M, Gomes A.R. Prevalence and antibiogram profile of bacterial isolates from clinical bovine mastitis. Vet. World. 2008; 1 (8):237238.

Tiwari J.G, Sandeep P, Chaudhari P.K, Tiwari H.K. Studies on incidence of mastitis in relation to stage and number of lactation. Indian Vet. J. 2008; 85:1232.

Tolosa T, Verbeke J, Piepers S, Supré K, de Vliegher S. Risk factors associated with subclinical mastitis as detected by California mastitis test in smallholder dairy farms in Jimma, Ethiopia using multilevel modelling. Prev. Vet. Med. 2013; 112:68-75.

Trevisi E, Zecconi A, Cogrossi S, Razzuoli E, Grossi P, Amadori M. Strategies for reduced antibiotic usage in dairy cattle farms. Res. Vet. Sci. 2014; 96:229-233.

\section{How to cite this article:}

Sambit Kumar Mishra, Sujata Kumari Panda and Debiprasanna Das. 2018. Incidence of Bovine Clinical Mastitis and Antibiogram of the Isolates in Odisha, India. Int.J.Curr.Microbiol.App.Sci. 7(09): 1122-1127. doi: https://doi.org/10.20546/ijcmas.2018.709.133 